\title{
The associated factors of Domestic Violence against Infertile Women
}

\author{
Fatemeh Alijani $^{1 *}$, Ahmad Khosravi ${ }^{2}$, Mahdieh Sadat Mousavi $^{3}$, Vanessa Delarosa ${ }^{4}$
}

1. Department of Reproductive Health and Midwifery, School of Nursing and Midwifery, Shahroud University of Medical Sciences, Shahroud, Iran.

2. Department of Epidemiology, School of Public Health,Shahroud University of Medical Sciences, Sharoud, Iran.

3. Varamin Azad University, Pishva Branch, Varamin, Iran.

4. Department of Health and Physical Activity, Friedrich University of Alexander Nuremberg, Germany.

*Correspondence: Department of Reproductive Health and Midwifery, School of Nursing and Midwifery, Shahroud University of Medical Sciences, Shahroud, Iran. Tel: +98-9119534721. Email: fatemehalijani1355@gmail.com

Received Sep 01, 2018; Accepted July 20, 2019

\section{Abstract}

Background: Domestic violence (DV) against women is a global public health concern. The study was conducted to determine the associated factors of domestic violence against infertile women.

Methods: This cross-sectional study was done on 379 infertile women referred to the infertility clinic in Sari, between October 2015 and March 2016. The convenience sampling was used considering inclusion criteria. Data was collected using Revised Conflict Tactics Scale (CTS2). Data was presented with descriptive statistics and Logistic regression to determine associated factors with DV in SPSS-16 software. The significant level was considered $\mathrm{P}<0.05$.

Results: Finding showed that majority of infertile women (88.9\%) experienced domestic violence. The age (OR=0.91 95\% CI: 0.85-0.99) and smoking (OR=8.12 95\% CI: 1.87-35.21) with domestic violence.

Conclusions: Regarding the high prevalence of domestic violence and its consequence on society, screening violence in health centers and support at-risk family via counseling are recommended.

Keywords: Domestic Violence, Infertility, Women, Prevalence, Risk Factors 


\section{Introduction}

Infertility usually refers to the inability to have a child after a year of regular intercourse without using any contraceptive (1). It is estimated that 120 to 180 million women aged from 18 to 49 are affected by this disorder around the world (2-4); however, its prevalence varies according to causes of infertility in different countries (3). An initial infertility rate of $24.9 \%$ has been reported in Iran (5). Despite the fact that the infertility is seen in women and men alike, according to the World Health Organization (WHO), it is commonly considered as a type of female disorder with a burden of responsibility on women $(6,7)$. This phenomenon is always associated with financial and emotional problems, aggression, stress, anger, divorce, isolation, frustration and violence (8-10).

Violence overshadows lives of millions of women across ethnic, cultural, religious, economic, and educational boundaries worldwide $(10,11)$, so that 5.3 million women over 18 years old are victims of domestic violence each year. Among them, two million get injured and 1400 die (1214). Violence is in fact any act based on the gender difference that may cause physical, sexual or psychological harm to women, lead to trauma, or even explicitly or implicitly threaten a person with the mentioned acts (15). This social problem not only poses a threat to physical and emotional health of women, but also affects family and society. According to WHO, one-third of women with sexual partners experience sexual or physical violence (15). On the other hand, the likelihood of violence in infertile women increases compared to women with children (16) and its prevalence varies among infertile women due to cultural, economic, and religious differences as it is reported equal to $31.2 \%, 31.6 \%, 64 \%$ and $77.8 \%$ in Nigeria, Turkey, Pakistan, and India respectively $(10,11,15,17)$. In Iran, the prevalence of domestic violence among infertile women varies in different studies with a frequency of $14 \%$ to $61.8 \%(9,18-20)$. Results of different studies indicate that depression, low self-esteem, anxiety, stress, suicide attempts, and sexual and physical problems are more likely to occur in victims of domestic violence (10, 15, and 21). Despite many studies on domestic violence, the impact of cultural, ethnic, and religious differences on the incidence rates and severity of its types and its significant effects on various aspects of individual and community health, on the one hand, and an inadequate number of studies, which considered infertile female as a target group, on the other hand, the present study aimed to investigate determinants of violence and its prevalence among infertile women in Sari, Iran.

\section{Methods}

This cross-sectional study was conducted on 379 infertile women referred to the infertility clinic affiliated to Sari University of Medical Sciences in 2015. The convenience sampling was used considering inclusion criteria. The inclusion criteria were being in the age range from 15 to 49 years; infertility with any reason; more than a year of marriage duration; and lack of physical or mental illness.

According to a study by Ardebili et al. (9) the prevalence of violence was about $60 \%$ and $d=0.05$, the sample size was estimated 384 using following formula: 


$$
\mathrm{N}=\frac{z^{2}(1-\alpha / 2) p q}{d^{2}}=\frac{4 \times 0.4 \times 0.6}{0.05^{2}}=384
$$

Data was collected using a two-part questionnaire including demographic and clinical information and the domestic violence scale. Demographic variables included age, educational level, employment status, place of residence; and clinical variables included duration of infertility and marriage, cousin marriage, male or female infertility, smoking, and spouse addiction status. The content validity of demographic checklist was approved by 7 faculty members.

The Domestic Violence Questionnaire consisted of 40 questions that were revised by Behboudi Moghaddam who confirmed its validity and reliability. The questionnaire assessed psychological violence with 12 questions, sexual violence with 8 questions, verbal violence with 6 questions, physical violence with 8 questions, and physical violence leading to injury with 6 questions. If any of the above areas was answered in the affirmative, the respondent was subjected to violence.

The permission of the study was obtained from the Research Deputy and Ethics Committee of Mazandaran University of Medical Sciences. Prior to study, necessary explanations were given by the questioner about the research purpose and confidentiality of information. Data was collected through interviews after completing the written informed consent by a trained researcher in a private place in the absence of spouses or family members. Data was analyzed in SPSS for Windows version 16.00 (SPSS Inc., Illinois, USA). Data are presented as mean values $\pm \mathrm{SD}$ and frequency. The Chi-square and independent t-tests to determine the associations of domestic violence and studied variables. The multivariate logistic regression was used to determine associations between independent variables and domestic violence. The significance level of all tests was considered less than 0.05 .

\section{Results}

The finding showed that the mean age of participants was $31.66 \pm 6.46$ years, range from 19 to 46 years. The spouses' mean of age was $35.99 \pm 8.40$ years, ranging from 20 to 70 years. Most of participants $(88.9 \%)$ reported that they experienced violence by their husbands; and the most reported type of violence was psychological one $(85.8 \%)$. (Table 1$)$

Table 1.Frequency of domestic violence in infertile women $(n=379)$

\begin{tabular}{|l|c|c|}
\hline Types of violence & $\mathbf{N}$ & \% \\
\hline Psychological & 325 & 85.5 \\
\hline Verbal & 183 & 48.3 \\
\hline Sexual & 109 & 28.8 \\
\hline Physical & 98 & 25.9 \\
\hline Physical leading to injury & 0 & 0 \\
\hline
\end{tabular}


Findings indicated that there was no significant relationship between domestic violence and the variables, namely women's educational status, spouse's job, place of residence, spouse's drug addiction, and cousin marriage. However, age, marriage duration, infertility duration, spouse's education, women's job status, and spousal cigarette smoking were significantly associated with violence $(\mathrm{P}<0.05)$. (Tables 2 and 3$)$

Table 2. Comparison of mean of some violence-related factors

\begin{tabular}{|l|c|c|c|}
\hline Variable & $\begin{array}{c}\text { With violence } \\
\text { Mean } \pm \text { SD }\end{array}$ & $\begin{array}{c}\text { Without violence } \\
\text { Mean } \pm \text { SD }\end{array}$ & P-value \\
\hline Age (years) & $31.08 \pm 6.22$ & $36.29 \pm 6.54$ & $<0.001$ \\
\hline Spouse's age (years) & $35.22 \pm 7.70$ & $42.12 \pm 11.02$ & $<0.001$ \\
\hline Marriage duration (years) & $6.91 \pm 4.64$ & $8.43 \pm 6.1$ & 0.05 \\
\hline Infertility duration (years) & $5.38 \pm 4.13$ & $7.05 \pm 6$ & 0.02 \\
\hline
\end{tabular}

Table 3. Association of violence with some relevant factors in infertile women $(n=379)$

\begin{tabular}{|c|c|c|c|}
\hline Variable & $\mathbf{N}$ & $\%$ & P-value \\
\hline $\begin{array}{l}\text { Education level } \\
\text { Illiterate } \\
\text { Under high school diploma } \\
\text { High school diploma } \\
\text { Academic }\end{array}$ & $\begin{array}{c}20 \\
85 \\
134 \\
98\end{array}$ & $\begin{array}{c}6 \\
25.2 \\
39.8 \\
29\end{array}$ & 0.91 \\
\hline $\begin{array}{l}\text { Spouse's education } \\
\text { Illiterate } \\
\text { Under high school diploma } \\
\text { High school diploma } \\
\text { Academic }\end{array}$ & $\begin{array}{c}26 \\
94 \\
135 \\
82 \\
\end{array}$ & $\begin{array}{c}7.7 \\
27.9 \\
40 \\
24.3\end{array}$ & 0.02 \\
\hline $\begin{array}{l}\text { Job status } \\
\text { Housewife } \\
\text { Employed } \\
\end{array}$ & $\begin{array}{c}277 \\
60 \\
\end{array}$ & $\begin{array}{l}82.2 \\
17.8 \\
\end{array}$ & 0.03 \\
\hline $\begin{array}{l}\text { Spouse's job status } \\
\text { Employed } \\
\text { Unemployed }\end{array}$ & $\begin{array}{c}331 \\
6\end{array}$ & $\begin{array}{c}98.2 \\
1.8\end{array}$ & 0.78 \\
\hline $\begin{array}{l}\text { Spouse's cigarette smoking } \\
\text { No } \\
\text { Yes }\end{array}$ & $\begin{array}{c}241 \\
96 \\
\end{array}$ & $\begin{array}{l}5.71 \\
28.5 \\
\end{array}$ & 0.005 \\
\hline $\begin{array}{l}\text { Spouse's drug addiction } \\
\text { No } \\
\text { Yes }\end{array}$ & $\begin{array}{c}292 \\
45\end{array}$ & $\begin{array}{l}7.86 \\
13.3 \\
\end{array}$ & 0.11 \\
\hline $\begin{array}{l}\text { Residential status } \\
\text { City } \\
\text { Village }\end{array}$ & $\begin{array}{l}225 \\
112\end{array}$ & $\begin{array}{l}8.66 \\
33.2\end{array}$ & 0.76 \\
\hline $\begin{array}{l}\text { Cousin marriage } \\
\text { No } \\
\text { Yes }\end{array}$ & $\begin{array}{c}259 \\
78\end{array}$ & $\begin{array}{l}9.76 \\
23.1\end{array}$ & 0.31 \\
\hline
\end{tabular}


The results of the multiple logistic regression indicated that the odds ratio of domestic violence decreased with increasing age of women, so that $9 \%$ of violence decreased for each year of increase in age (adjusted odds ratio of 0.91 with $95 \%$ confidence interval between 0.85 to 0.99 , $\mathrm{p}=0.03$ ). History of spousal cigarette smoking also increased the odds of violence against women more than eight times (adjusted odds ratio of 8.12 with $95 \%$ confidence interval between 1.87 to $35.21, \mathrm{p}=0.005$ ). (Table 4 )

Table 4. Relationships between demographic characteristics and domestic violence using logistic regression model $(n=379)$

\begin{tabular}{|l|c|c|c|c|}
\hline \multicolumn{1}{|c|}{ Variable } & $\begin{array}{c}\text { crude odds ratio } \\
\text { (95\% confidence inter- } \\
\text { val) }\end{array}$ & P-value & $\begin{array}{c}\text { Adjusted odds ratio } \\
\text { (95\% confidence } \\
\text { interval) }\end{array}$ & P-value \\
\hline Age (year) & $0.88(0.84-0.93)$ & 0.001 & $0.91(0.85-0.99)$ & 0.03 \\
\hline Spouse's age (year) & $0.92(0.89-0.95)$ & 0.001 & $0.95(0.91-1.01)$ & 0.16 \\
\hline Marriage duration (year) & $0.94(0.89-1)$ & 0.05 & $1.09(0.96-1.23)$ & 0.16 \\
\hline Infertility duration (year) & $0.93(0.87-0.99)$ & 0.02 & $0.90(0.79-1.03)$ & 0.15 \\
\hline $\begin{array}{l}\text { Job status } \\
\text { Housewife } \\
\text { Employed }\end{array}$ & $\begin{array}{c}0.23(0.05-0.98) \\
\text { Reference }\end{array}$ & 0.04 & $0.26(0.06-1.15)$ & 0.07 \\
\hline $\begin{array}{l}\text { Spouse's smoking } \\
\text { No } \\
\text { Yes }\end{array}$ & $\begin{array}{c}\text { Reference } \\
7.96(1.88-33.61)\end{array}$ & 0.005 & $8.12(1.87-35.21)$ & 0.005 \\
\hline
\end{tabular}

\section{Discussion}

In the present study, the prevalence of domestic violence was $88.9 \%$ among infertile women, while domestic violence had a prevalence of $31 \%-76 \%$ among infertile women in other studies in Iran, Turkey, Pakistan, India and Nigeria $(9-11,17,19,20,23,24)$. This difference might be due to differences in methods, the use of different questionnaires, socio-cultural differences among women in different countries or even different regions of a country.

The collection of samples at the State Infertility Center, in which the clients were generally those with lower educational, social and economic status, was among factors that justified the high prevalence of violence in the present study. Therefore, the results of the present study could not indicate the overall status of infertile women, and thus it was a limitation of the present study. The high prevalence of psychological violence with a frequency of $85.8 \%$ increased the overall prevalence of violence. Among different types of violence, verbal violence accounted for the second frequent type in almost half of the women. Despite high prevalence of violence, no injury by violence was reported by any of the participants. Identical to the findings of the present research, several studies have identified psychological violence as the most common form of violence $(9,19,20,25-27)$. Some studies in Iran reported the prevalence of psychological violence $74.3 \%, 82 \%$ and $87.3 \%$ that were very close to findings of the present study $(20,25$, 28). However, a research in Nigeria reported a higher incidence (94\%) than the present study (23). Unlike the obtained results in the present study, Yildizhan et al. conducted a study on 70 people in Turkey and reported the verbal violence with a frequency of $63.4 \%$ as the most 
common type of violence (10), while it was introduced as the second most prevalent type in the present study. Less than one-third of the research participants had experienced sexual violence, and it was lower than a study by Abadi et al. on 80 people among whom more than half of the participants had experienced sexual violence (25). Contrary to obtained findings of the present study, a high prevalence of sexual violence was observed in Nigeria (82.9\%) (23). It is worth noting that the absence of sexual violence leading to injury in the present study was inconsistent with a research by Ardebili et al. who reported that the prevalence of this type of violence was $6 \%$ (9). According to the previous studies, no other study had examined the physical injury among infertile women. This difference in prevalence of different types of violence in different studies can be attributed to different individual perceptions of violence, research design, report method, target group, and cultural, religious and social norms and beliefs in different societies.

The present study did not indicated any relationship between domestic violence and the variables of educational status of women, spouse's job status, place of residence, drug abuse by spouse, and cousin marriage, but the relationship between women's age and employment status was significant. Contrary to the above results, Ardebili et al. noted a significant relationship between domestic violence in infertile women and spouse's unemployment (9). Despite the significant relationships between violence and women's age and job status in the present study, Akyüz et al. found no relationship between mentioned cases and violence (24). The relationships between violence and demographic variables is controversial due to the differences in various abovementioned studies. For instance, relationships between violence and some demographic variables were not significant in some studies, but a significant relationship was found between them in other studies $(9,17,23,24)$. In terms of residence place, several studies have identified rural living as a factor in increasing violence $(25,29)$; and this result was inconsistent with studies in India and Ghana that found urban life to be associated with increased violence $(30,31)$. Consistent with findings of the present study, other studies found no relationship between residence place and violence $(32,33)$. These differences can be explained by differences in cultural, economic and welfare characteristics and available facilities in cities and villages in different societies. Violence against women is a global problem that covers all people beyond geographical boundaries, and economic and educational status (24). In explaining findings of the present study, Akyuz et al. found a significant relationship between violence and duration of infertility (34), and their results were inconsistent with studies in Iran and Nigeria (9, 27). Despite the insignificance of relationship between violence and spouse addiction in the present study, a similar study in Kermanshah indicated that more than half of the participants with a history of violence had addicted spouses (25).

Among all studied variables in the present study, spousal smoking status and women at younger age were independent predictors of violence in infertile women. Results of the present study indicated that spousal smoking status increased the odds ratio of violence by 8 times; and it was consistent with results of some other studies $(35,36)$.

In the present study, there are strengths such as identifying the most prevalent type of violence in infertile women and weaknesses such as failure to investigate the cause of increased violence with spousal smoking status and women at younger age. Future studies should investigate these issues through using standardized tools to collect data from fertile and infertile women, and compare the violence between two groups. Cluster sampling should be done from all public and private areas to reflect overall social level (15). Cultural constraints in developing countries make the intervention of this importance issue difficult to some extent. Therefore, it is necessary 
to raise the couples' awareness and education about mutual rights and anger management through counseling centers and the mass media.

\section{Conclusion}

The results of the present study indicated a high prevalence of violence among infertile women. Considering the psychological violence as the most common type of violence, it is clear that spousal cigarette smoking and women at younger age than spouses were among predictors of violence. Given the impact of domestic violence on women's health, it seems necessary to identify at-risk women by healthcare staff and pay special attention to them through design and implementation of appropriate interventions such as training programs, for instance, communication skills and problem-solving approaches.

\section{Acknowledgements}

The present research was derived from a master's thesis on midwifery counseling that approved and funded by Shahroud University of Medical Sciences with Code of Ethics (9303). We are grateful for the Research Deputy of Shahroud and Mazandaran Universities of Medical Sciences as well as officials and colleagues of Imam Khomeini Infertility Centers of Sari and all participants who contributed to this project.

\section{References}

1. Zegers-Hochschild F, Adamson GD, de Mouzon J, Ishihara O, Mansour R, Nygren K, et al. The international committee for monitoring assisted reproductive technology (ICMART) and the world health organization (WHO) revised glossary on ART terminology. Hrp. 2009; 24(11):2683-7.

2. Mascarenhas MN, Flaxman SR, Boerma T, Vanderpoel S, Stevens GA. National, regional, and global trends in infertility prevalence since 1990: a systematic analysis of 277 health surveys. PLoS medicine. 2012; 9(12):e1001356.

3. Van Der Poel SZ. Historical walk: the HRP Special Programme and infertility. Gynecol Obstet Investig. 2012; 74(3):218-27.

4. Rutstein S, Shah I: Infecundity, infertility, and childlessness in developing countrie. DHS Comparative Reports No 9 Calverton, ORC Macro, World Health Organization, 2004.

5. Vahidi S, Ardalan A, Mohammad K. Prevalence of primary infertility in the Islamic Republic of Iran in 2004-2005. Asia Pac J Public Health 2009; 21(3):287-93.

6. Espada AÁ, Moreno-Rosset C. Psychological intervention in infertility: guidelines for a clinical intervention protocol. Papeles del psicòlogo. 2008; 29(2):186-96.ARTs. 2015; 94(3):318-27. 
7. Dyer SJ, Abrahams N, Mokoena N, Lombard CJ, van der Spuy ZM. Psychological distress among women suffering from couple infertility in South Africa: a quantitative assessment. Hum Reprod. 2005; 20(7):1938-43.

8. Greil AL, Slauson-Blevins K, McQuillan J. The experience of infertility: a review of recent literature. Sociol Health Illn .2010; 32(1):140-62.

9. Ardabily HE, Moghadam ZB, Salsali M, Ramezanzadeh F, Nedjat S. Prevalence and risk factors for domestic violence against infertile women in an Iranian setting. Int J Gynaecol Obstet. 2011; 112(1):15-7.

10. Yildizhan R, Adali E, Kolusari A, Kurdoglu M, Yildizhan B, Sahin G. Domestic violence against infertile women in a Turkish setting. Int J Gynaecol Obstet .2009; 104(2):110-2.

11. Aduloju PO, Olagbuji NB, Olofinbiyi AB, Awoleke JO. Prevalence and predictors of intimate partner violence among women attending infertility clinic in south-western Nigeria. Eur J Obstet Gynecol Reprod Biol, 2015; 188:66-9.

12. Wilson JS, Websdale N. Domestic violence fatality review teams: An interprofessional model to reduce deaths. J Interprof Care.2006; 20(5):535-44.

13. Houry D, Kemball R, Rhodes KV, Kaslow NJ. Intimate partner violence and mental health symptoms in African American female ED patients. Am J Emerg Med.2006; 24(4):444-50.

14. Sato-DiLorenzo A, Sharps PW. Dangerous intimate partner relationships and women's mental health and health behaviors. Issues in mental health nursing.2007; 28(8):837-48.

15. Geneva (Switzerland). Violence against women: fact sheet N 239. WHO. OCT 2013; 29(8):239-50.

16. Stellar C, Garcia-Moreno C, Temmerman M, van der Poel S. A systematic review and narrative report of the relationship between infertility, subfertility, and intimate partner violence. Int J Gynaecol Obstet. 2016; 133(1):3-8.

17. Sami N, Ali TS. Domestic violence against infertile women in Karachi, Pakistan. ARSS. 2012; 1(1):15.

18. Behboodi MZ, Eftekhar AH, Salsali M, Ramezanzadeh F, Nedjat S. Physical and psychological violence against infertile women. JFRH .2010; 4(2):65-7.

19. Farzadi L, Ghasemzadeh A, Asl ZB, Mahini M, Shirdel H. Intimate partner violence against infertile women. JCRG. 2014; 3(2):147-51.

20. Sheikhan Z, Ozgoli G, Azar M, Alavimajd H. Domestic violence in Iranian infertile women. Med J Islam Repub Iran. 2014; 28(1): 152. 
21. Petok, W. (2006). The Psychology of Gender-Specific Infertility Diagnoses. In S. Covington \& L. Burns (Eds.), Infertility Counseling: A Comprehensive Handbook for Clinicians (pp. 37-60). Cambridge: Cambridge University Press.

22. Straus MA, Hamby SL, Boney-McCoy S, Sugarman DB. The revised conflict tactics scales (CTS2) development and preliminary psychometric data. JFI.1996; 17(3):283-316.

23. Iliyasu Z, Galadanci HS, Abubakar S, Auwal MS, Odoh C, Salihu HM, Et al. Phenotypes of intimate partner violence among women experiencing infertility in Kano, Northwest Nigeria. Int J Gynaecol Obstet. 2016; 133(1):32-6.

24. Akyüz A, Şahiner G, Seven M, Bakır B. The effect of marital violence on infertility distress among a sample of Turkish women. Int J Fertil Steril. 2014; 8(1):67.

25. Abadi MP, Mahdavi S, Esmaeili K, Amighi M, Hashemian AH. The amount of domestic violence in Kermanshahi (a provincial center in west Iran) women given birth in 20112012. WJMMSR 2014; 11(2):202-206. [persian]

26. Hasanpoor-Azghdy SB, Simbar M, Vedadhir A. The social consequences of infertility among Iranian women: a qualitative study. Int J Fertil Steril. 2015; 8(4):409.

27. Ameh N, Kene T, Onuh S, Okohue J, Umeora O, Anozie O. Burden of domestic violence amongst infertile women attending infertility clinics in Nigeria. Niger J Med. 2007; $16(4): 375-7$.

28. Guruge S, Roche B, Catallo C. Violence against women: an exploration of the physical and mental health trends among immigrant and refugee women in Canada. Nursing research and practice. 2012; 2012.

29. Faramarzi M, Esmailzadeh S, Mosavi S. Prevalence and determinants of intimate partner violence in Babol City, Islamic Republic of Iran. East Mediterr Health J.2005; 11(56):870-9.

30. Sinha A, Mallik S, Sanyal D, Dasgupta S, Pal D, Mukherjee A. Domestic violence among ever married women of reproductive age group in a slum area of Kolkata. Indian J Public Health .2012; 56(1):31.

31. Adjah ESO, Agbemafle I. Determinants of domestic violence against women in Ghana. BMC public health. 2016; 16(1):368.

32. Parish WL, Wang T, Laumann EO, Pan S, Luo Y. Intimate partner violence in China: national prevalence, risk factors and associated health problems. Int Fam Plan Perspect. 2004; 30(4):174-81.

33. Al Dosary AH. Health impact of domestic violence against Saudi women: cross sectional study. Int. J. Med. Sci 2016; 10(2):165.

34. Akyuz A, Seven M, Şahiner G, Bilal B. Studying the effect of infertility on marital violence in turkish women. Int J Fertil Steril. 2013; 6(4):286. 
35. Aklimunnessa K, Khan MM, Kabir M, Mori M. Prevalence and correlates of domestic violence by husbands against wives in Bangladesh: evidence from a national survey. JMHG. 2007; 4(1):52-63.

36. Gil-Gonzalez D, Vives-Cases C, Alvarez-Dardet C, Latour-Perez J. Alcohol and intimate partner violence: do we have enough information to act?. Eur J Public Health.2006; 16(3):278-84.

\section{Bibliographic information of this paper for citing:}

Alijani F, Khosravi A, Mousavi MS, et al. The effects of nursing welcome program on the level of stress and satisfaction of patients in the Coronary Care Unit.

J Res Dev Nurs Midw, 2019; 16(2): 61-70.

Copyright (C 2019, Fatemeh Alijani, Ahmad Khosravi, Mahdieh Sadat Mousavi, Vanessa Delarosa 